\author{
Article \\ Microstructure and selected properties of $\mathrm{Ni}-\mathrm{Cr}$-Re coatings \\ deposited by means of plasma thermal spraying \\ Konrad Tobota 1,* (D), Marcin Chmielewski ${ }^{(\mathbb{D}}$, Ján Dusza $^{3}$ (D) \\ 1 Warsaw University of Technology, Poland \\ 2 Łukasiewicz Research Network Institute of Electronic Materials Technology, Poland \\ Marcin.Chmielewski@itme.edu.pl (M.C.) \\ 3 Institute of Materials Research Slovak Academy of Science, Slovak Republic \\ jdusza@imr.saske.sk (J.D.) \\ * Correspondence: konradtob@gmail.com (K.T.)
}

Received: 01.03.2020; Accepted: date 11.06.2020

\begin{abstract}
The article presents the results of research on plasma sprayed Ni-Cr-Re coatings. The substrate was $16 \mathrm{Mo} 3$ chromium-molybdenum steel used in the production of boilers. The coatings were sprayed

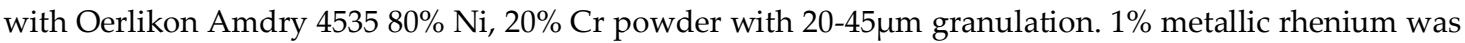
added to the base powder using a high energy ball milling method. Rhenium is a heavy, high-density metal. As an alloying addition, it improves the heat resistance of alloys, creep resistance and high temperature oxidation. Rhenium alloys are widely used in the energy and aviation industries as an alloying additive to prevent creep. Observations were made on an optical microscope and a SEM microscope. Hardness tests and optical surface testing with a profilometer were carried out.
\end{abstract}

Keywords: plasma; flame spraying; coating

\title{
Introduction
}

Plasma spraying involves melting the appropriate coating materials in the plasma arc in the form of wire or powder and transporting the plasticized particles to the substrate. Metallic, ceramic and even composite powders are commonly used. Powder spray torches are similar in operation to welding and surfacing torches. These are torches with an internal, independent arc (Fig. 1). Spraying is carried out under various atmospheric conditions, depending on the technological requirements of the final coating, in reduced-pressure chambers, in a vacuum and in controlled atmospheres. The most commonly used plasma forming gas in the spraying process is argon or a mixture of argon and hydrogen, which increases plasma enthalpy [1]. Coatings with a thickness of $0.05 \div 2 \mathrm{~mm}$ and a density of up to $98 \%$ are obtained. The efficiency when spraying metals is up to $10 \mathrm{~kg} / \mathrm{h}$, while when spraying with ceramic powders $3.5 \div 4.5 \mathrm{~kg} / \mathrm{h}$. The quality

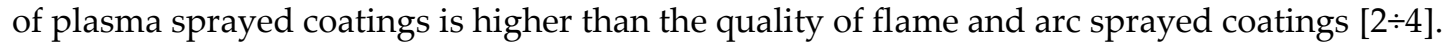

In the plasma method it is possible to use a wide range of coating materials (non-ferrous metals, ceramics and their mixtures with metals, composites) [5]. The properties of the obtained coating depend largely on the coating material used (powder, wire, metal, ceramics), its chemical affinity with the substrate material and the preparation of the substrate's surface immediately before the process. In addition to the chemical, physical and metallurgical factors mentioned above, the parameters of the process itself are also extremely important, i.e. the distance of the torch from the ground, powder or wire flow, gas flow rate and others [6,7]. A properly prepared substrate surface and precisely selected process parameters result in good adhesion, quality and low porosity of the obtained coatings. A well-prepared surface is considered to be a dry, degreased surface, free from oxides and impurities, and above all with appropriate roughness. The surface profile should be irregular and heterogeneous and have a kind of "nests" in which it will be possible to deposit striking particles of plasticized material [8,9].

The purpose of this work is to develop a technology for plasma spraying of nickel-chromium powder with the addition of Rhenium (Ni-Cr-Re) onto a 16Mo3 boiler steel substrate and characterization of the coating.

Rhenium is a refractory dark silvery element from the group of transition metals with an atomic number of 75 and an atomic mass of 186.2 . It has a very high melting point $\left(3180^{\circ} \mathrm{C}\right)$ the third highest after carbon and tungsten. Young's modulus (470 GPa). It is characterized by the fourth highest density $\left(21.02 \mathrm{~g} / \mathrm{cm}^{3}\right)$, 
giving place to osmium, iridium and platinum. At $2700 \div 2800{ }^{\circ} \mathrm{C}$ and high stress conditions, rhenium tensile strength and high temperature creep are significantly higher than tungsten (at temperatures up to $1250{ }^{\circ} \mathrm{C}$ it exceeds twice). The unique properties of rhenium are used everywhere where we deal with extremely high temperature values. It is used in the aviation and rocket industry for the production of jet engine components, in the electrotechnical industry, on electrical contacts where temperature values are extremely high, or in the energy industry. The addition of rhenium to $\mathrm{Ni}-\mathrm{Cr}$ powder is to increase the heat resistance of the obtained

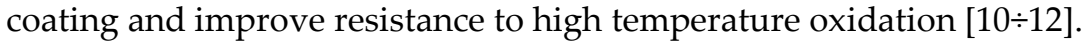

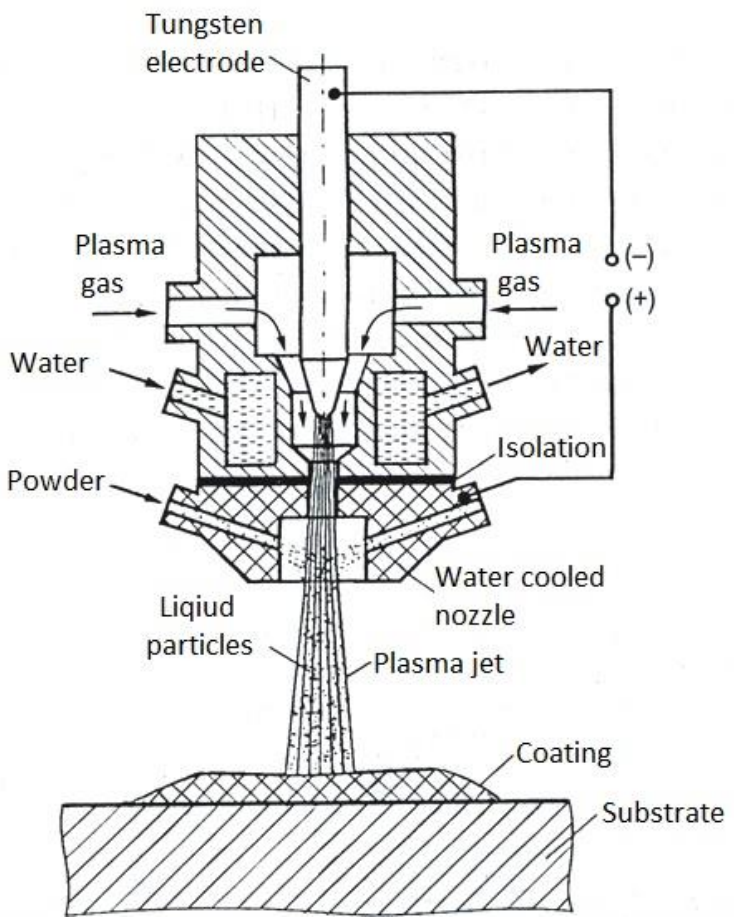

Fig. 1. Diagram of plasma spraying process [4]

\section{Materials and devices}

The base material was boiler steel, low alloy 16Mo3. Used in the energy industry for the construction of boilers, pipelines and pressure vessels. The chemical composition of this steel is shown in table I.

The coating was sprayed on 100x50x4 mm plates.

Mechanical properties according to EN 10273:2007:

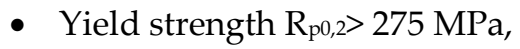

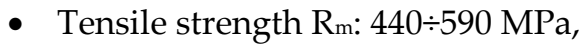

- Elongation $\mathrm{A}>24 \%$

- Yield strength at $500{ }^{\circ} \mathrm{C} \mathrm{R}_{\mathrm{p} 0,2}=141 \mathrm{MPa}$,

- Creep resistance at $500{ }^{\circ} \mathrm{C} \mathrm{R}_{\mathrm{z} 100000}=90 \mathrm{MPa}$.

The base additional material was Oerlikon Amdry 4535 nickel chromium powder enriched with 1\% (wt.) of pure metallic rhenium. The chemical composition of the powder is presented in table II.

Table I. Chemical composition of 16Mo3 steel [9]

\begin{tabular}{cccccccccccc}
\hline \multirow{2}{*}{ Standard } & $\mathbf{C}$ & $\mathbf{S i}$ & $\mathbf{M n}$ & $\mathbf{P}$ & $\mathbf{S}$ & $\mathbf{A l}$ & $\mathbf{N}$ & $\mathbf{C r}$ & $\mathbf{C u}$ & $\mathbf{M o}$ & $\mathbf{N i}$ \\
& {$[\%]$} & {$[\%]$} & {$[\%]$} & {$[\%]$} & {$[\%]$} & {$[\%]$} & {$[\%]$} & {$[\%]$} & {$[\%]$} & {$[\%]$} & {$[\%]$} \\
\hline EN 10028-2:2009 & $0,12 \div 0,20$ & 0,35 & $0,40 \div 0,90$ & 0,025 & 0,010 & - & 0,012 & 0,30 & 0,30 & $0,25 \div 0,35$ & 0,30 \\
\hline
\end{tabular}

Table II. Chemical composition of Oerlikon Amdry 4535 powder [8]

\begin{tabular}{cccccc}
$\mathbf{N i}$ & $\mathbf{C r}$ & $\mathrm{Si}$ & $\mathbf{F e}$ & $\mathbf{M n}$ & Others (max) \\
{$[\%]$} & {$[\%]$} & {$[\%]$} & {$[\%]$} & {$[\%]$} & {$[\%]$} \\
\hline Base & 19,5 & 0,75 & 0,25 & 0,25 & 0,4 \\
\hline
\end{tabular}

The morphology of the base powder without the addition of rhenium is shown in figure 2. Fractions with spheroidal geometry can be observed, whose diameter oscillates within $20 \div 45 \mu \mathrm{m}$.

Metallic rhenium powder was characterized by an irregular shape and different particle sizes in the range of $2 \div 10 \mu \mathrm{m}$. The Re powder morphology is shown in figure 3 . 


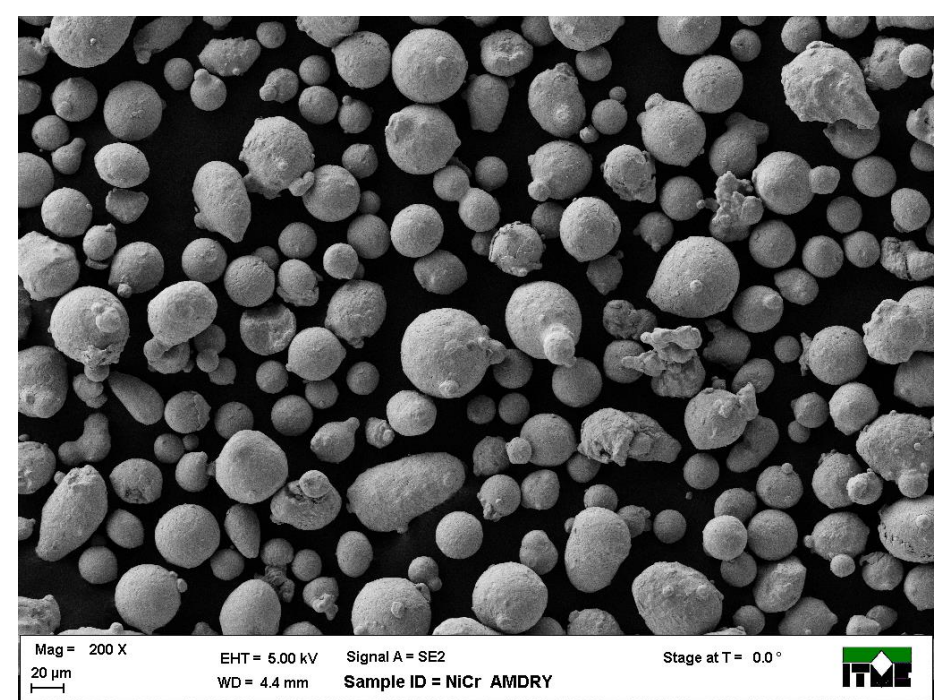

Fig. 2. Morphology of Oerlikon powder AMDRY 4535 (SEM)

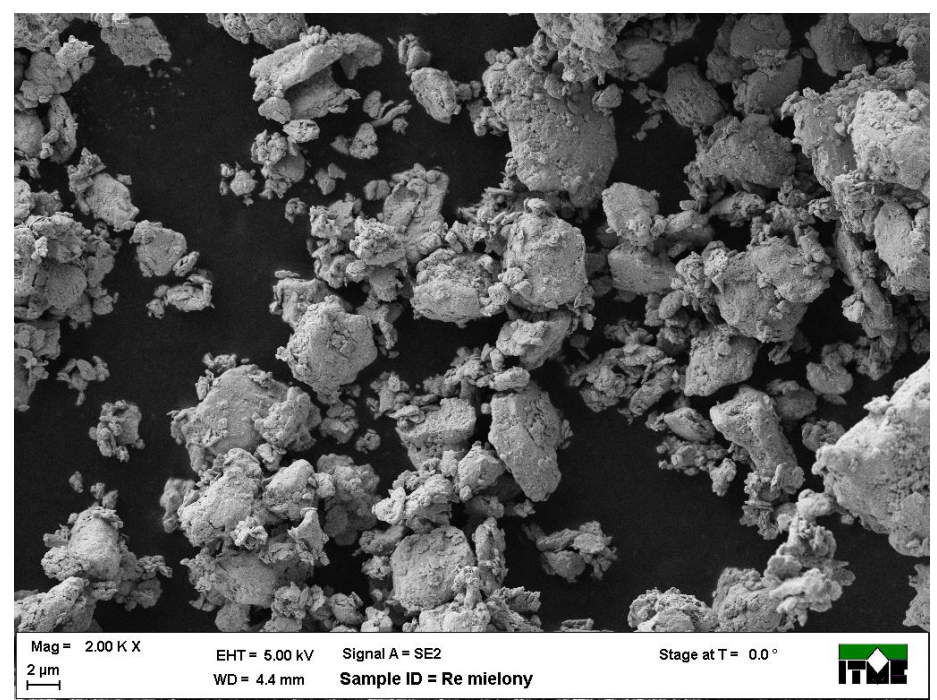

Fig. 3. Morphology of Re metallic powder (SEM)

The target coating material used for spraying was created as a result of high-energy milling in the ball mill of the powders described earlier with $1 \%$ by weight of rhenium. Figure 4 shows the morphology of the resulting mixture. A back-scattered ions detector was used to generate material contrast distinguishing atoms of different atomic numbers. Re heavier than the nickel-chromium matrix gives a clear picture that can be seen as the lighter irregular fractions surrounding the $\mathrm{Ni}-\mathrm{Cr}$ spheroidal particles.

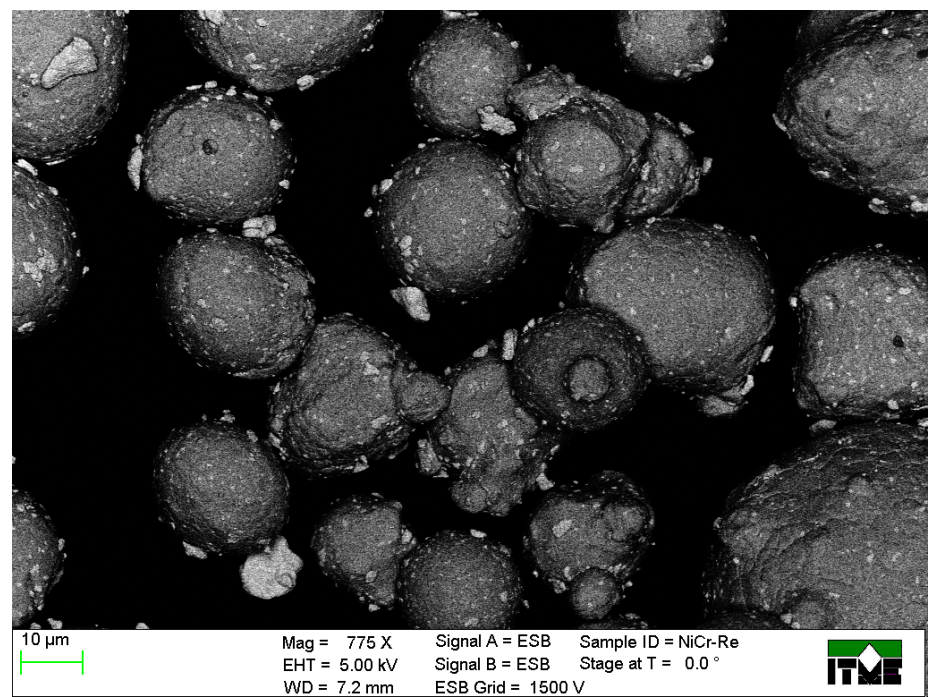

Fig. 4. Morphology of mixture of Ni-Cr-Re powder (SEM) 
Spraying tests were carried out using the Multiprocess Spray System MP100 device at Certech. Prior to the spraying process, the powder was dried at $300{ }^{\circ} \mathrm{C}$ for $50 \mathrm{~h}$ and sieved through a $50 \mu \mathrm{m}$ sieve. 10 steel plates were welded to the steel C-profile to avoid shifts during spraying, allowing for a homogeneous coating and better heat dissipation. The substrate was shot blasted with F36 fused alumina. The roughness Ra after treatment was on average $6.5 \mu \mathrm{m}$. The channel section was attached to the stand's vertical truss (Fig. 5). The plasma forming gas was a mixture of argon and helium. The additive material in the form of a powder was fed with an argon stream.

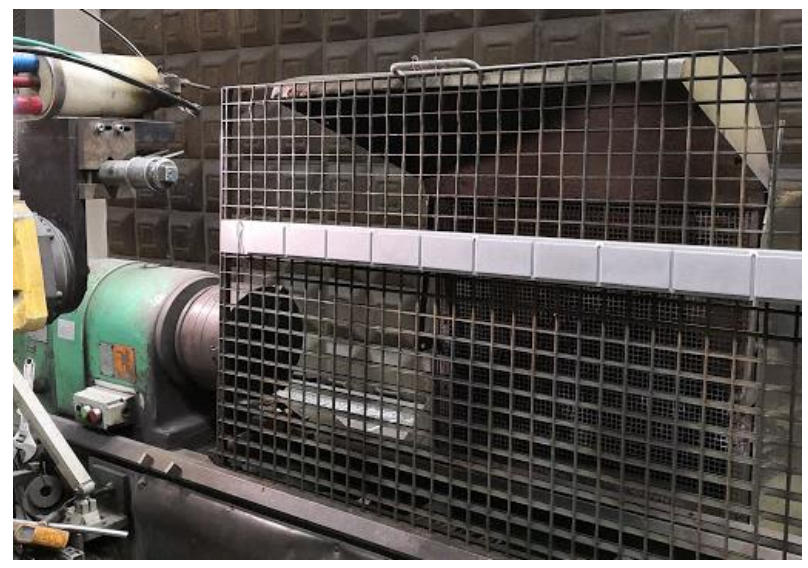

Fig. 5. Method of fixing plasma spray samples on a common beam

The F4 plasma torch is mounted on the FANUC R-100iA robot arm, which allows unlimited, free generation of the plasma torch trajectory. Thanks to this, the process was carried out repeatedly, precisely maintaining a constant distance between the torch and the ground. Table III presents the process parameters, figure 6 directly shows the spraying process itself. According to the assumptions, a coating thickness of approx. $500 \mu \mathrm{m}$ was obtained.

Table III. Plasma spraying parameters

\begin{tabular}{lc} 
Amperage [A]: & 530 \\
Voltage [V]: & 33,5 \\
the burner to the ground [mm]: & 130 \\
H$_{2}$ flow rate [1/min]: & 9 \\
Ar flow rate [1/min]: & 54 \\
orch feed rate [mm/s]: & 250 \\
Powder feeding gas & $\mathrm{Ar}$ \\
\hline
\end{tabular}

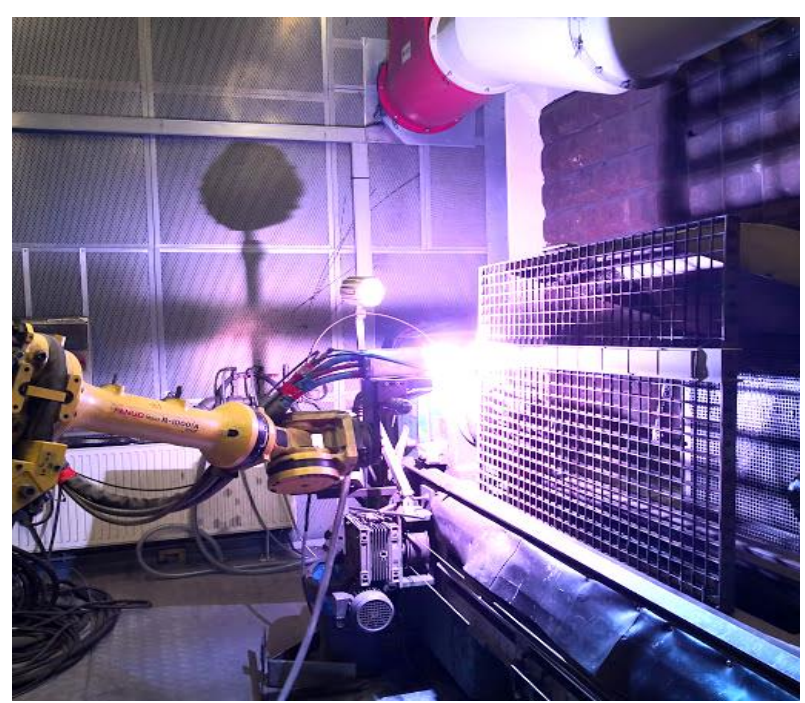

Fig. 6. Plasma spraying process

The temperature of the substrate material was monitored during the process. After the sprayed substrate reached $130{ }^{\circ} \mathrm{C}$, the process was stopped. After cooling to room temperature, subsequent layers 
were sprayed until the substrate material reached a temperature of $130{ }^{\circ} \mathrm{C}$ again. The cooling was assisted by a stream of air.

\section{Examination of the obtained coatings}

Prior to the start of destructive testing, optical roughness measurements were carried out on a Sensofar $S$ Neox profilometer. Roughness measurements of the steel substrate after shot blasting and of the coating were carried out. Substrate surface parameters are summarized in table IV.

Table IV. Surface parameters of the substrate material after shot blasting process [5]

\begin{tabular}{lc}
\hline \multicolumn{2}{c}{ Amplitude parameters - Roughness profile } \\
\hline $\mathbf{R p}$ & $57,9789 \mu \mathrm{m}$ Gaussian filter, $0,8 \mathrm{~mm}$ \\
$\mathbf{R v}$ & $25,9135 \mu \mathrm{m}$ Gaussian filter, $0,8 \mathrm{~mm}$ \\
$\mathbf{R z}$ & $83,8925 \mu \mathrm{m}$ Gaussian filter, $0,8 \mathrm{~mm}$ \\
$\mathbf{R c}$ & $55,8867 \mu \mathrm{m}$ Gaussian filter, $0,8 \mathrm{~mm}$ \\
$\mathbf{R t}$ & $86,3550 \mu \mathrm{m}$ Gaussian filter, $0,8 \mathrm{~mm}$ \\
$\mathbf{R a}$ & $9,29516 \mu \mathrm{m}$ Gaussian filter, $0,8 \mathrm{~mm}$ \\
$\mathbf{R q}$ & $12,2660 \mu \mathrm{m}$ Gaussian filter, $0,8 \mathrm{~mm}$ \\
$\mathbf{R s k}$ & $1,08806 \mu \mathrm{m}$ Gaussian filter, $0,8 \mathrm{~mm}$ \\
\hline
\end{tabular}

The average arithmetic deviation of the profile from the medium line Ra oscillates close to $9 \div 10 \mu \mathrm{m}$. However, this is a parameter that does not give clear information about the profile course and the actual distribution of the height of the unevenness. An important parameter is the Rz value, i.e. the average height of 10 extreme surface points ( 5 above the medium line and 5 below the medium line). Rz values of approx. $85 \mu \mathrm{m}$ testify to the heterogeneous and irregular profile course and ensure unevenness in the surface facilitating sticking of the coating particles. To illustrate the surface profile, a three-dimensional model was made (Fig. 7).

On the model, we observe clear irregularities, which promotes the adhesion of the coating. A height deviation from the medium line was also generated on the control measuring section (Fig. 8).

The course of height on the control measuring section confirms the correctness of measurement of the $\mathrm{Rz}$ parameter. Deviations from the medium line reach up to $50 \mu \mathrm{m}$. For comparison purposes, measurements were also made of the surface profile of the coating after plasma spraying (Fig. 9). The set of surface parameters of the coating is summarized in table $\mathrm{V}$.

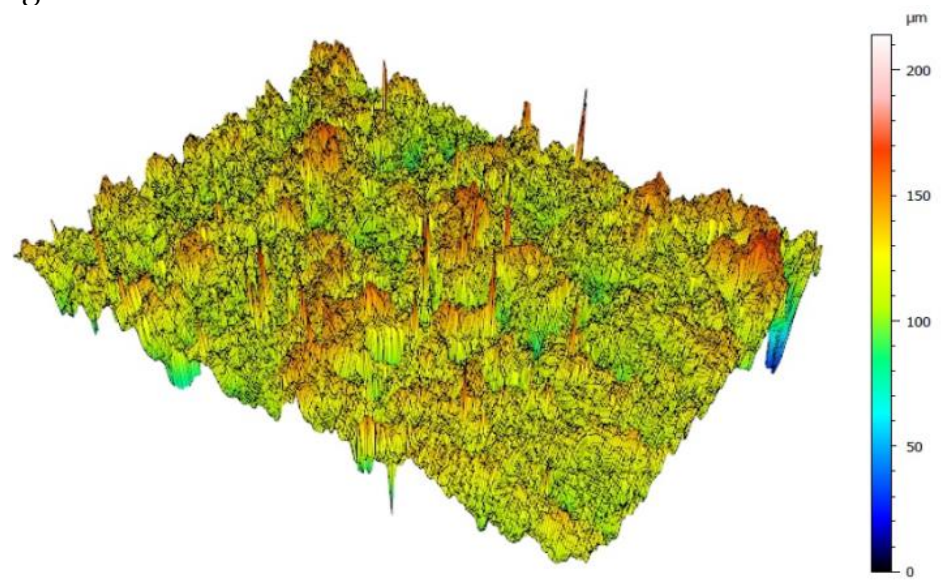

Fig. 7. Three-dimensional map of the substrate surface

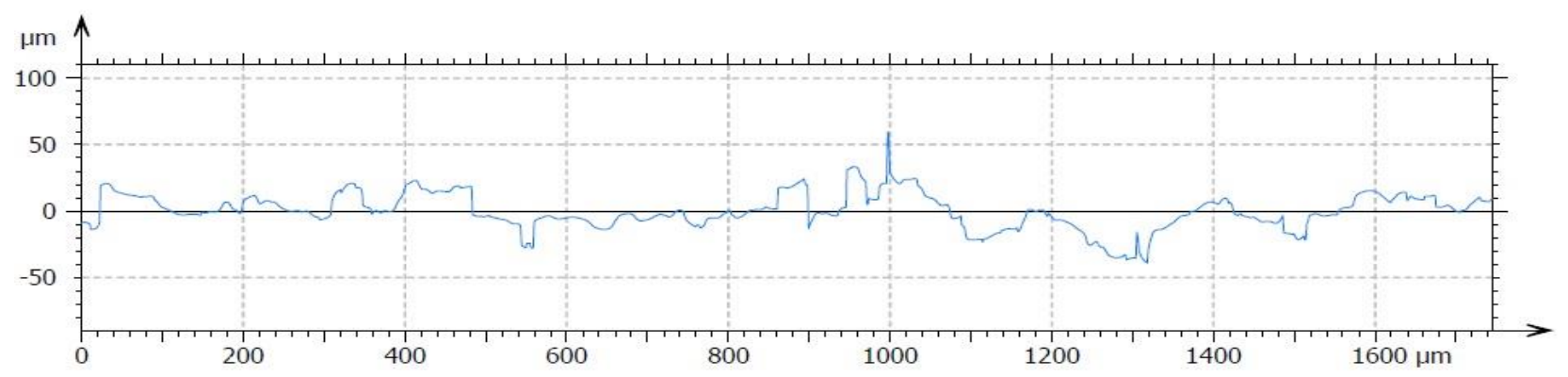

Fig. 8. Course of deviation from the medium line of the substrate after shot blasting 
Table V. Surface roughness parameters of the plasma sprayed coating

\begin{tabular}{cc}
\hline \multicolumn{2}{c}{ Amplitude parameters - Roughness profile } \\
\hline $\mathrm{Rp}$ & $27,7902 \mu \mathrm{m}$ Gaussian filter, 0,8 mm \\
$\mathrm{Rv}$ & $19,9584 \mu \mathrm{m}$ Gaussian filter, 0,8 mm \\
$\mathrm{Rz}$ & $47,7485 \mu \mathrm{m}$ Gaussian filter, 0,8 mm \\
$\mathrm{Rc}$ & $21,2852 \mu \mathrm{m}$ Gaussian filter, $0,8 \mathrm{~mm}$ \\
$\mathrm{Rt}$ & $50,3044 \mu \mathrm{m}$ Gaussian filter, $0,8 \mathrm{~mm}$ \\
$\mathrm{Ra}$ & $7,69356 \mu \mathrm{m}$ Gaussian filter, $0,8 \mathrm{~mm}$ \\
$\mathrm{Rq}$ & $9,30530 \mu \mathrm{m}$ Gaussian filter, $0,8 \mathrm{~mm}$ \\
$\mathrm{Rsk}$ & $0,358240 \mu \mathrm{m}$ Gaussian filter, $0,8 \mathrm{~mm}$ \\
\hline
\end{tabular}

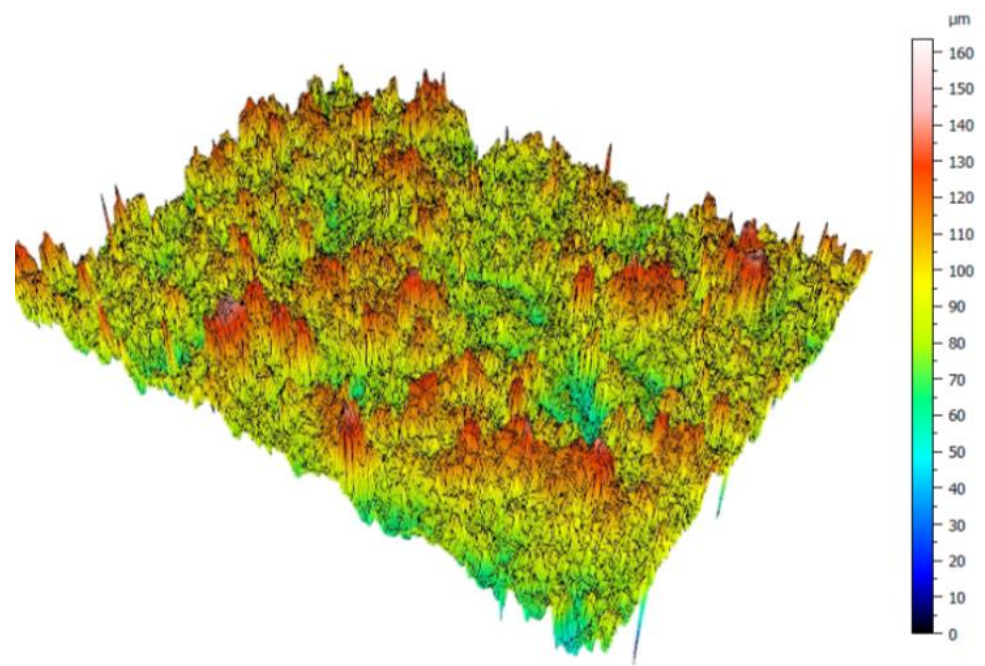

Fig. 9. Three-dimensional map of coating surface deposited by the means of plasma spraying

The resulting coating has a lower roughness than the substrate. The Ra parameter oscillates close to 7.69 $\mu \mathrm{m}$. The average height of 10 extreme surface points $\mathrm{Rz}$ of approx. $48 \mu \mathrm{m}$ is almost twice smaller than for the surface of the substrate after shot blasting.

Compared to the substrate's surface, the height distribution of extreme unevenness is clearly lower, the surface profile is more uniform. The course of deviation from the medium line (Fig. 10) is also milder.

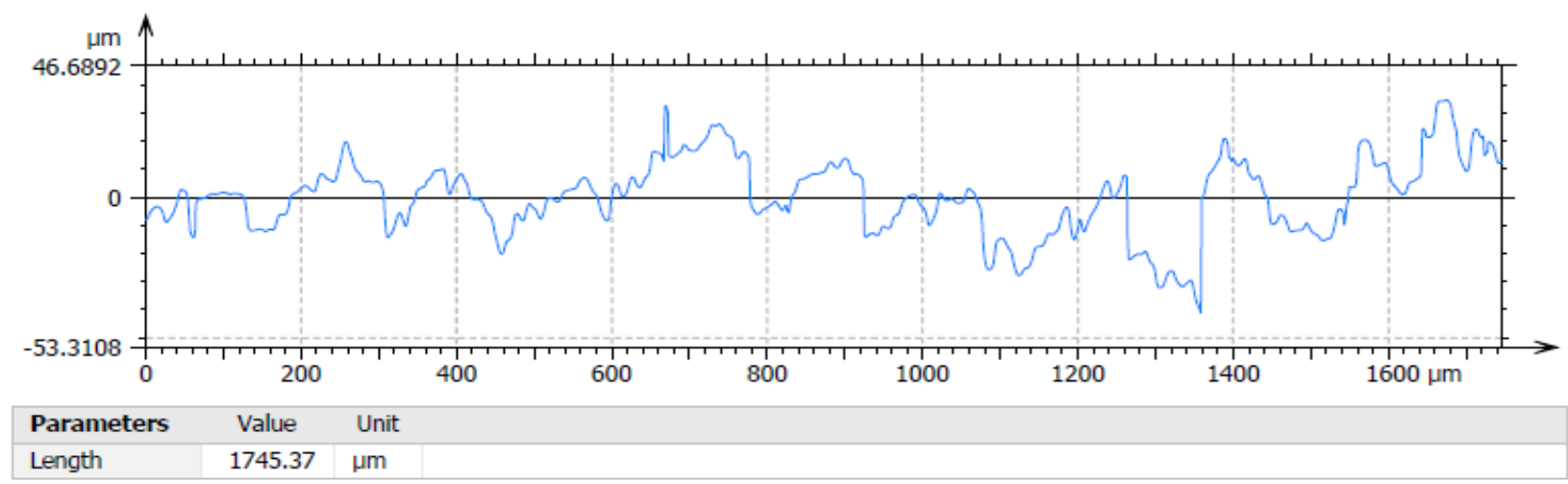

Fig. 10. Course of deviation from the medium line of the sprayed coating surface

Figure 11 shows the microstructure of the substrate-coating system. The $16 \mathrm{Mo} 3$ steel substrate with a ferritic-pearlitic structure is characterized by an even grain distribution. An oxide layer characteristic for spraying processes was observed on the transition line (Fig. 11b). The coating thickness is about $500 \mu \mathrm{m}$.

Figure 12 shows the microstructure of the coating and substrate observed using an electron microscope using a back-scattered ion detector. The light-coloured phase represents the distribution of Re particles in the coating, the weight proportion of which is about $1 \%$.

The coating structure consists of deformed Ni-Cr matrix powder particles in which inclusions (light particles in the SEM image) are randomly dispersed in the form of Re particles with dimensions of several micro-meters (Fig. 13). 


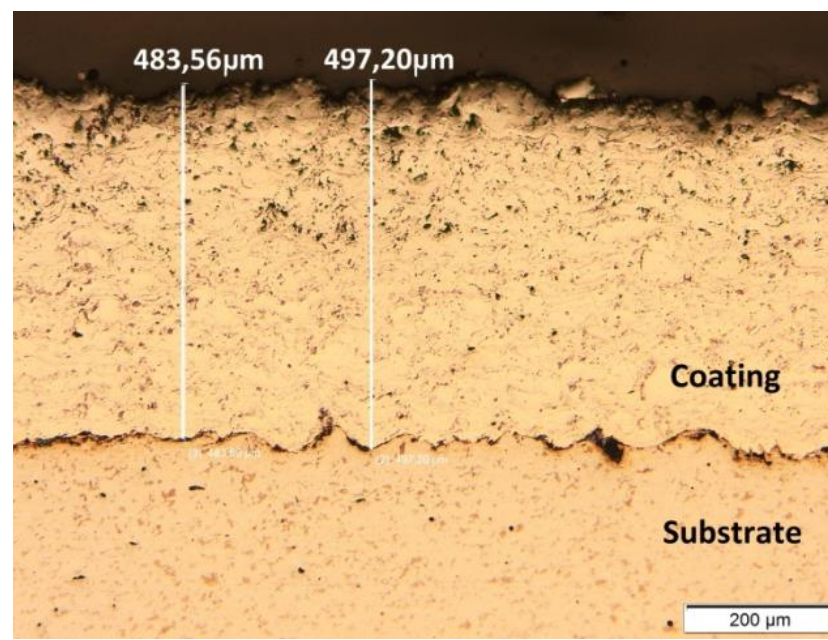

(a)

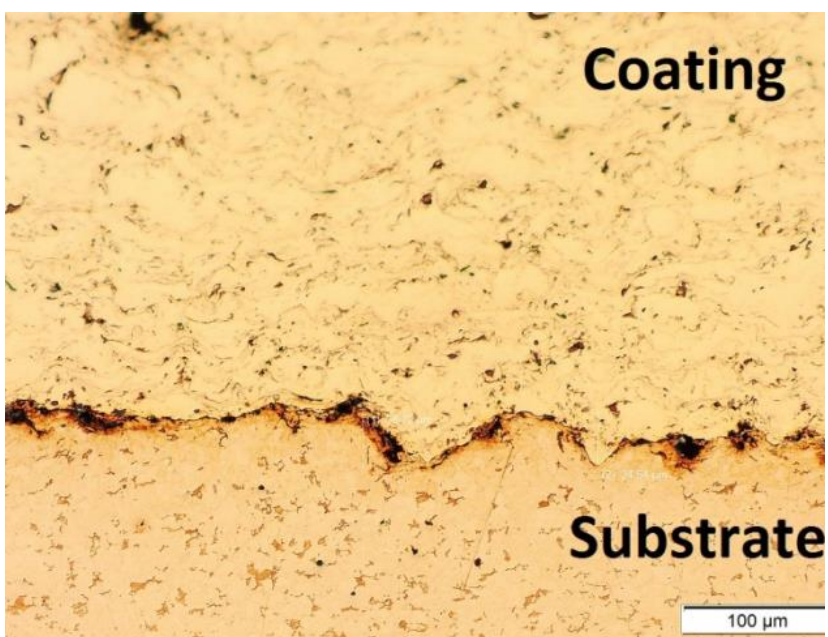

(b)

Fig. 11. Microstructure of $16 \mathrm{Mo} 3$ steel substrate and Ni-Cr-Re coating

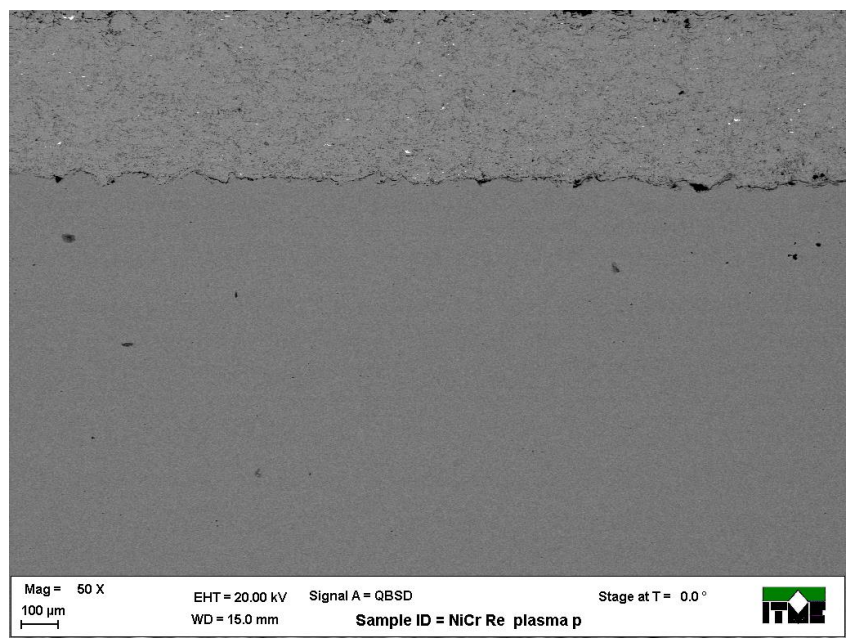

Fig. 12. Microstructure of substrate and Ni-Cr-Re coating (SEM)

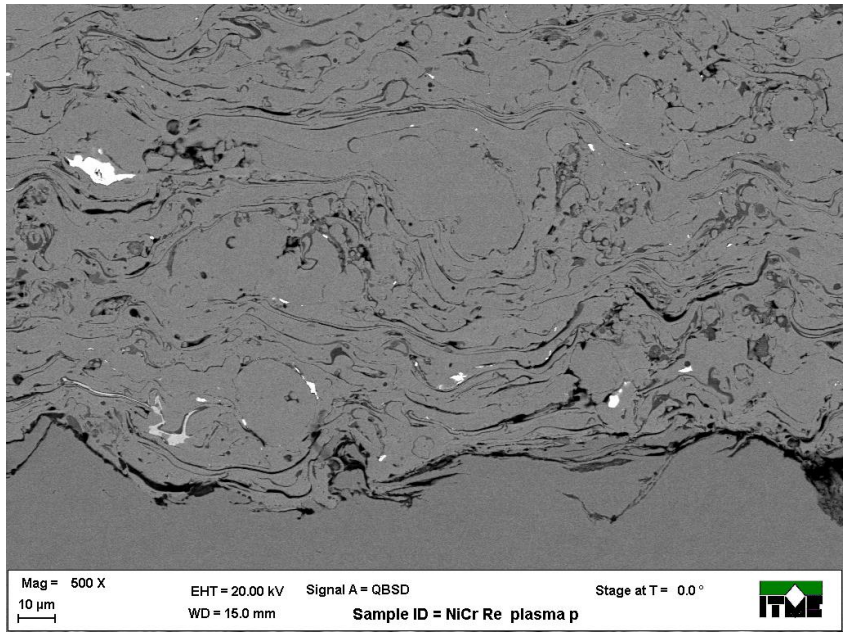

Fig. 13. Microstructure of substrate and Ni-Cr-Re coating (SEM)

In the next stage, the hardness of the coating was measured by the Vickers method according to EN ISO 6507-1. The measurements were carried out under a load of $2 \mathrm{~N}$, and the results are illustrated in a graph (Fig. 14).

The graph shows the average hardness value over 5 measurement series with a standard deviation for the measurement point at a 95\% confidence level. The measurement imprints were taken in $60 \mu \mathrm{m}$ steps. The hardness of the $16 \mathrm{Mo} 3$ steel substrate is approximately $180 \mathrm{HV} 0.2$ with a relatively low standard deviation, which indicates homogeneity of the substrate material. The coating has a hardness in the range of 
$220 \div 240 \mathrm{HV} 0.2$, with nearly twice the value of the standard deviation from the average values. This confirms the heterogeneity and diverse structure of the coating.

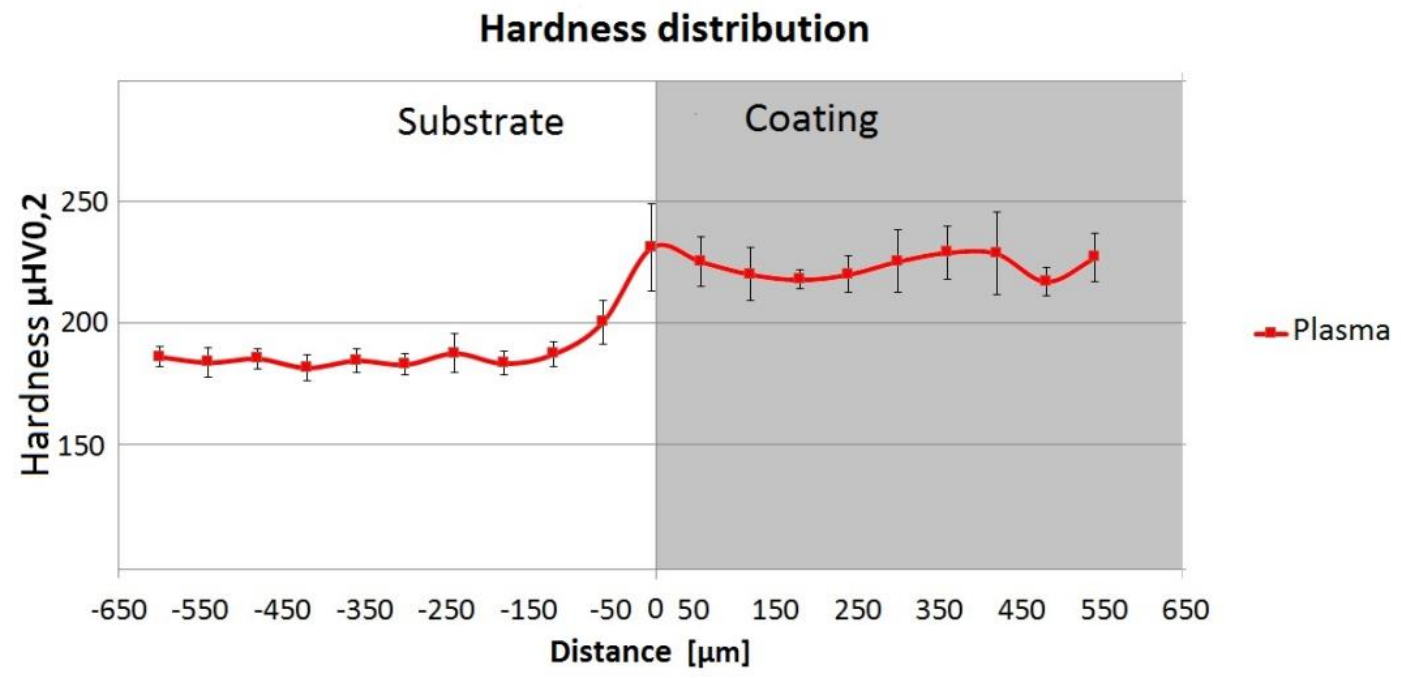

Fig. 14. Hardness distribution in substrate-coating system

\section{Summary and Conclusions}

The plasma spraying process is characterized by high flexibility of application. With appropriate selection of parameters, we can use dissimilar metallic, ceramic and composite additional materials. The sprayed coatings are characterized by low porosity. In many cases it is a good alternative to conventional welding methods. The coating material based on nickel and chromium is characterized by high corrosion resistance. The addition of metallic rhenium to the powder increases the heat resistance of the alloy obtained during the process. A protective coating with such a chemical composition increases the resistance to high temperature oxidation. Correct coatings with correct adhesion to the substrate were obtained. Oxide layers on the transition line and between subsequent applied layers are a common defect that is visible in the microscopic images of the structure. This is characteristic of sprayed coatings. The obtained $\mathrm{Ni}-\mathrm{Cr}$-Re plasma sprayed coating has a slightly higher hardness than the ferritic-pearlitic substrate of $16 \mathrm{Mo} 3$ steel, oscillating around the value of 230 HV0.2. The coating structure reveals relatively uniformly dispersed Re particles, which are easily identified due to their high density. On the microscopic image, we observe them in the form of bright inclusions with dimensions of several micro-meters.

Author Contributions: conceptualization, M.C. and K.T.; methodology, J.D.; software, K.T.; validation, M.Ch., J.D. and K.T.; formal analysis, M.C.; investigation, K.T.; resources, M.C.; data curation, M.C.; writing - original draft preparation, K.T.; writing - review and editing, K.T.; visualization, K.T.; supervision, M.C.; project administration, M.C.; funding acquisition, M.C.

Funding: This research was funded by NCBR „Innovative Ni-Cr-Re coatings with enhanced corrosion and erosion resistance for high temperature applications in power generation industry" grant number NICRRE project4249 M-ERA.NET Call 2016, agreement number M-ERA.NET2/2016/01/2017

Acknowledgments: The authors of the article would like to thank Mr. Mariusz Władowski (OPTOTOM ul. Głębocka 54c, Warsaw) for his help in conducting surface roughness tests.

Conflicts of Interest: The authors declare no conflict of interest.

\section{References}

[1] Fauchais P., Montavon G., Vardelle M., Cedelle J., Developments in direct current plasma spraying. Surface and Coatings Technology, 2006, Vol. 201(5), 1908-21. https://doi.org/10.1016/j.surfcoat.2006.04.033

[2] Chmielewski T., Hudycz M., Krajewski A., Salaciński T., Skowrońska B., Świercz R., Structure investigation of titanium metallization coating deposited onto aln ceramics substrate by means of friction surfacing process. Coatings, 2019, Vol. 9(12). https://doi.org/10.3390/coatings9120845

[3] Chmielewski T., Metallization of AlN Ceramic with Ti Using Detonation Spraying Process - Thermodynamic Approach. Journal of Manufacturing Technologies, 2018, Vol. 43(1), 11-9.

[4] Łatka L., Thermal Barrier Coatings Manufactured by Suspension Plasma Spraying - A Review. Advances in Materials Science, 2018, Vol. 18(3), 95-117. https://doi.org/10.1515/adms-2017-0044 
[5] Vardelle M., Fauchais P., Vardelle A., Li K.I., Dussoubs B., Themelis N.J., Controlling particle injection in plasma spraying. Journal of Thermal Spray Technology, 2001, Vol. 10(2), 267-84. https://doi.org/10.1361/105996301770349367

[6] Liu T., Planche M.P., Kanta A.F., Deng S., Montavon G., Deng K., et al., Plasma spray process operating parameters optimization based on artificial intelligence. Plasma Chemistry and Plasma Processing, 2013, Vol. 33(5), 1025-41. https://doi.org/10.1007/s11090-013-9475-3

[7] Michalak M., Łatka L., Sokołowski P., Comparison of mechanical properties of the plasma sprayed coatings by powder and suspension. Welding Technology Review, 2017, Vol. 89(10), 56-60. https://doi.org/10.26628/wtr.v89i10.819

[8] Pawlowski L., Suspension and solution thermal spray coatings. Surface and Coatings Technology, 2009, Vol. 203(19), 2807-29. https://doi.org/10.1016/j.surfcoat.2009.03.005

[9] Varacalle D.J., Guillen D.P., Deason D.M., Rhodaberger W., Sampson E., Effect of grit-blasting on substrate roughness and coating adhesion. Journal of Thermal Spray Technology, 2006, Vol. 15, 348-55. https://doi.org/10.1361/105996306X124347

[10] Giamei A.F., Anton D.L., Rhenium additions to a Ni-base superalloy: Effects on microstructure. Metallurgical Transactions A, 1985, Vol. 16, 1997-2005. https://doi.org/10.1007/BF02662400

[11] Czech N., Schmitz F., Stamm W., Improvement of MCrAlY coatings by addition of rhenium. Surface and Coatings Technology, 1994, Vol. 68-69, 17-21. https://doi.org/10.1016/0257-8972(94)90131-7

[12] Tobota K., Chmielewski T., Chmielewski M., Microstructure and Selectedproperties of Ni-Cr-Re Coatings Deposited by Means of HVOF Thermal Spraying. Welding Technology Review, 2019, Vol. 91(1), 25-30. https://doi.org/10.26628/wtr.v91i1.1000

(C) 2020 by the authors. Submitted for possible open access publication under the terms and conditions of the Creative Commons Attribution (CC BY) license (http://creativecommons.org/licenses/by/4.0/). 